picture of brief psychotic episodes evolving into a picture of dementia. He fitted into the description of late-onset ICBG described by Cummings et al. ${ }^{1}$

$\mathrm{He}$ had exposure to antipsychotic drugs for nearly 2 years but these were already discontinued for 3 years when he was referred to us. As his psychotic illness and treatment with antipsychotic drugs preceded the abnormal movements, it remains possible that part of his movement disorder can be attributed to tardive dyskinesia. Furthermore, excessive susceptibility of ICBG patients to the extrapyramidal effects of antipsychotics has been noted by various authors ${ }^{1,2}$ as some of these patients had also received antipsychotic treatment prior to the onset of their movement disorder. However, the patient's parkinsonian features could not be accounted for by tardive dyskinesia and is likely to be related to ICBG.

We hope that this report will heighten clinicians' awareness of this rare entity and we recommend that ICBG should be considered as a differential diagnosis in pscyhiatric patients with a movement disorder.

\title{
References
}

1. Cummings, J.L., Gosenfield, L.F., Houlihan, J.P. \& McCaffrey, T. Neuropsychiatric disturbances associated with idiopathic calcification of the basal ganglia. Biol Psychiatry 1983, 18: 591-601.

2. Francis, A.F. Familial basal ganglia calcification and schizophreniform psychosis. Br J Psychiatry 1979, 135: 360-362.

3. Boller, F., Boller, M. \& Gilbert, J. Familial idiopathic cerebral calcification. J Neurol Neurosurg Psychiat 1977, 40: 280-285.

4. Kane, J.M., Woerner, M. \& Lieberman, J. Tardive dyskinesia: Prevalence, incidence and risk factors. J Clin Psychopharmacol 1988, 8: $528-556$.
5. Kalamboukis, Z. \& Molling, P. Symmetrical calcification of the brain in the predominance in the basal ganglia and cerebellum. J Neuropathol Exp Neurol 1962, 21: 364-371.

6. Trautner, R.J., Cummings, J.L., Read, S.L. \& Benson, F Idiopathic basal ganglia calcification and organic mood disorder. Am J Psychiatry 1988, 145: 350-353.

7. Wylie, K.R. \& Harris, S.J. Idiopathic basal ganglia calcification presenting as hypomania. Int J Geriatr Psychiatry 1990, 51: $401-402$.

8. König, P. Psychopathological alterations in cases of symmetrical basal ganglia sclerosis. Biol Psychiat 1989, 25: 459-468.

\section{Pulmonary alveolar microlithiasis presenting with chronic cough}

\author{
Ipek Türktas, Sezen Saribas and Ferhun Balkanci ${ }^{1}$
}

\author{
Dr Sami Ulus Children's Hospital, Ankara, and 'Department of Radiology, Hacettepe University \\ Faculty of Medicine, Ankara, Turkey
}

\begin{abstract}
Summary: A case of a 10 year old boy with pulmonary alveolar microlithiasis is presented. Although most children with this disease are asymptomatic, our patient had persistent cough for more than 3 years. It is likely that his chronic cough was a direct consequence of the disease.
\end{abstract}

\section{Introduction}

Pulmonary alveolar microlithiasis (PAM) is a rare disease of unknown aetiology characterized by the presence of multiple microscopic stones within the pulmonary alveoli. Most patients with PAM have no symptoms and many others have minor or questionable symptoms when their disease is first diagnosed. The pattern in our patient follows that

Correspondence: I. Türktas, M.D., Bülten Sok 42/5, 06700 Kavaklidere, Ankara, Turkey.

Accepted: 20 July 1992 described in many cases in the literature but chronic cough has been seldom reported. ${ }^{1,2}$

\section{Case report}

A 10 year old boy had been complaining of dry cough for 6 months and his chest $\mathrm{X}$-ray showed bilateral dense miliary mottling. He was diagnosed as having miliary tuberculosis by a local physician. The cough persisted following 6 months of antituberculosis therapy and the chest X-ray remained unchanged. He was referred to our hospital in 
August 1988 for further investigation. His present history of illness revealed a non-productive cough but no history of breathlessness or a haemoptysis. Physical examination including a thorough otolaryngological examination was completely normal. Urine analysis, complete blood count, routine blood biochemistry tests and sweat chloride concentration were within normal limits. A sinus radiograph was normal. Chest X-ray revealed bilateral, diffuse calcified micronodules (Figure 1). Resting arterial blood gas values in room air were within normal limits. The lung function test values were thought to indicate a mild restrictive lung disease and absence of significant airway obstruction. The provocative concentration of methacoline required to decrease forced expiratory volume in one second $\left(\mathrm{FEV}_{1}\right)$ by $20 \%$ $\left(\mathrm{PC}_{20}\right)$ was $16 \mathrm{mg} / \mathrm{ml}$. The result of a barium swallow under fluoroscopic control was normal. The patient was diagnosed as having PAM and antituberculous therapy was stopped. His chronic cough has persisted, the chest X-ray appearance and lung function test values remain unchanged.

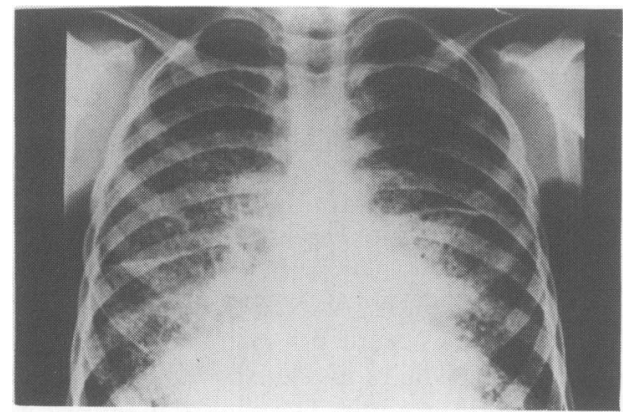

Figure 1 Chest X-ray showing bilateral, diffuse calcified micronodules.

\section{References}

1. O'Neill, R.P., Cohn, E.E. \& Pellegrino, E.D. Pulmonary alveolar microlithiasis. A family study. Ann Intern Med 1967, 67: 957-967.

2. Fuleihan, F.J.D., Abboud, R.T., Balikian, J.P. \& Nucho, C.K.N. Pulmonary alveolar microlithiasis: lung function in five cases. Thorax 1969, 24: 84-89.

3. Prakash, U.B.S., Barham, S.S., Rosenow, E.C., Brown, M.L. \& Payne, W.S. Pulmonary alveolar microlithiasis. A review including ultrastructural and pulmonary function studies. Mayo Clin Proc 1983, 58: 290-300.

4. Miro, J.M., Moreno, A., Coca, A., Segura, F. \& Soriano, E. Pulmonary alveolar microlithiasis with an unusual radiological pattern. Br J Dis Chest 1982, 76: 91-96.

5. Harlin, S.L., Ansel, D.G., Lane, S.R., Myers, J., Kephart, G.M. \& Gleich, G.J. A clinical and pathologic study of chronic sinusitis: the role of the eosinophil. $J$ Allergy Clin Immunol 1988, 81: 867-875.

\section{Discussion}

PAM has been reported from many areas of the world since $1933 .^{3}$ The precise onset of the disease has never been determined. Although definitive diagnosis requires lung biopsy, most investigators believe that the $\mathrm{X}$-ray appearance is unique and that the diagnosis may be made on this basis alone and lung biopsy is seldom necessary. ${ }^{3,4}$ The diagnosis in our case was made by the characteristic 'sandstorm' appearance on chest X-ray, the mild restrictive pattern of pulmonary function tests and the discrepancy between the paucity of physical signs and radiographic abnormality.

In our patient chronic cough was the major complaint and had persisted for more than 3 years. The four most common causes of chronic cough: postnasal drip, ${ }^{5}$ asthma, ${ }^{6}$ gastrooesophageal reflux ${ }^{7}$ and psychogenic cough ${ }^{8}$ were effectively excluded, since the patient had no symptoms of postnasal drip and a sinus radiograph was normal, had not demonstrated the presence of hyperreactive airways by a negative methacoline inhalation challenge, had a normal barium swallow and coughed also during sleep which is not the case in psychogenic cough.

It is difficult to explain the pathogenesis of persistent cough in PAM. One possible mechanism would be the stimulation of $\mathrm{C}$-fibre endings between larynx and alveoli by the mechanical force of microliths filling the alveoli. ${ }^{9}$ As previously reported, microliths may also be found in bronchial walls, ${ }^{10}$ thus causing a cough reflex by stimulating rapidly adapting receptors.

Our patient's cough was unresponsive to therapeutic trials of antitussive medicines, so we cannot recommend any specific therapy.

6. Connell, E.J.O., Rojas, A.R. \& Saches, M.I. Cough-type asthma: a review. Ann Allergy 1991, 66: 278-285.

7. Ing, A.J., Ngu, M.C. \& Breslin, A.B.X. Chronic persistant cough and gastrooesophageal reflux. Thorax 1991, 46: 479-483.

8. Shuper, A., Mukamel, M., Mimouni, M., Lerman, M. \& Varsano, I. Psychogenic cough. Arch Dis Child 1983, 58: 745-747.

9. Reisman, J.J., Canny, G.J. \& Levison, H. The approach to chronic cough in childhood. Ann Allergy 1988, 61: 163-169.

10. Sears, M.R., Chang, A.R. \& Taylor, A.J. Pulmonary alveolar microlithiasis. Thorax 1971, 26: 704-711. 